Arbeitsmethoden der modernen Naturwissenschaften 



\title{
Vektor- und Dyadenrechnung für Physiker und Techniker
}

\author{
Von \\ ERWIN LOHR \\ Professor an der Deutschen Technischen Hochschule \\ in Brünn
}

Mit 34 Figuren im Text

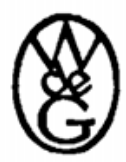

Berlin 1939

W A L TER D E GR U Y T R \& C O. vormals G. J. Göschen'sche Verlagshandlung / J. Guttentag. Verlagsbuchhandlung / Georg Reimer / Karl J. Trübner , Veit \& Comp. 
Alle Rechte, insbesondere das der Ubersetzung vorbehalten. Copyright 1939 by Wal ter de Gru y te r \& C o., vormals G. J. Goschen'sche Verlagshandlung - J. Guttentag, Verlagsbuchhandlung - Georg Reimer - Karl J. Trübner - Veit \& Comp. Berlin W 35, Woyrschstrabe 13. Archiv-Nr. 526239.

Printed in Germany. - Druck von Metzger \& Wittig in Leipzig 